\title{
MUNDO PRO. ANATOMÍA DE UN \\ PARTIDO FABRICADO PARA GANAR
}

de Gabriel Vommaro,

Sergio Morresi y Alejandro Bellotti,

Editorial Planeta, Buenos Aires, 2015.

PAULINA POLETTI

Facultad de Humanidades y Ciencias -

Universidad Nacional del Litoral

Este libro, pionero en el análisis del partido Propuesta Republicana (PRO), se organiza en diez capítulos que pueden agruparse en cinco bloques temáticos. El primero de ellos, que abarca los tres primeros apartados, hace un recorrido por los inicios de PRO, la biografía de Mauricio Macri y otros referentes partidarios, así como el proceso por el cual se incorporaron las distintas piezas a este armado político. Este es concebido como un fruto de la crisis de representación de 2001, que dejó en «estado de disponibilidad» a buena parte del electorado porteño, por un lado, y huérfanos a cuadros de diversas fuerzas, por el otro. Se sostiene que PRO es un rompecabezas que se compone de cinco grupos que mantienen relaciones de conflicto y cooperación entre sí, a saber: figuras provenientes del Partido Justicialista y la Unión Cívica Radical, sectores ligados a la ex Unión de Centro Democrático y la derecha tradicional católica, los «PRO puros» (jóvenes profesionales egresados de universidades de élite llegados del mundo de las fundaciones y ONG's) y, por último, los empresarios. En este rompecabezas Macri juega el rol de «armonizador» entre las distintas piezas de un partido que se muestra como plural pero que no permite el internismo. La imagen de un team leader se condice -explican los autores- con el ideal muy arraigado en Argentina de una sociedad sin conflictos. Pero Macri es, además, el aglutinante y el mayor capital político de PRO: si «Mauricio» avanza en su carrera, todos lo hacen.

El segundo bloque ofrece un repaso de la gestión macrista en la Ciudad Autónoma de Buenos Aires y explica por qué PRO es una fuerza de derecha. Sus dos valores centrales son la idea de sociedad sin conflictos -motivo por el cual rechaza la división izquierda/derecha y se apoya en valores "posmateriales» (como, por ejemplo, la ecología) - y la eficiencia. También se exponen las principales deficiencias de su 
paso por el gobierno, como el deterioro de la salud y la educación pública, el proceso de "gentrificación», el aumento en publicidad oficial y la frecuente utilización del poder de veto. Pero además PRO puede ser considerado de derecha por la forma en que la mayoría de sus miembros piensan la relación Estado-mercado, los derechos humanos o la inmigración, como así también por las redes internacionales de pensamiento y las internacionales partidarias a las que pertenece. Sin embargo, más allá de las simpatías o rechazos que pueda suscitar, hay un dato que merece ser celebrado: la derecha, aunque no se reconozca como tal, ha decidido participar del juego democrático.

Por su parte, el capítulo sexto, que conforma el tercer eje temático, aborda la estrategia de marketing. La puesta en escena de los rituales partidarios "cuya estética es similar a la de un festejo familiar» está pensada en función de la presencia de los medios de comunicación y procura seducir al elector con un discurso emotivo y alegre, lo que le permite a PRO llegar a donde sus redes partidarias no logran hacer pie. Además, los expertos en publicidad y encuestas ofrecen una guía de acción a los «PRO puros» que carecen de experiencia política, aunque esto no significa una renuncia a la construcción de una política basada en las relaciones personales y de anclaje territorial y social. Por último, PRO llevó la lógica publicita- ria a la gestión cotidiana y, como consecuencia de esta "campaña permanente», sus colores y los del Estado se fusionaron. De este modo, la "pasión por el hacer» concreto, slogan de PRO, devino en «pasión por comunicar».

El cuarto eje, que comprende del séptimo al noveno capítulo, trata cuestiones como la militancia, el trabajo territorial y la relación con el mundo espiritual. Con respecto a la primera, los Jóvenes PRO encarnan el atributo definitorio del partido, que erige a la juventud como un valor opuesto a «la vieja política». Y para ascender en esta organización -en la que los actores compiten por el favor de Macri para ocupar puestos en el partido y el Estado-, es necesario acreditar militancia social, concebida como una virtud moral, y el perfeccionamiento técnico. En relación a la dimensión territorial, aunque PRO abrace paulatinamente la participación de los habitantes de las villas, su relación con ellos continúa siendo tensa. El partido tiende a favorecer una política a pequeña escala en los barrios en los que tiene mayor capacidad de control, como «Los Piletones». Este caso, que ocupa todo un capítulo, expone la existencia de una «afinidad electiva» entre el trabajo de Margarita Barrientos y las ideas del PRO: la asociación de voluntarios que sin banderas partidarias recurre a donaciones de privados para asistir a los necesitados, construye el bienestar de los pobres no 
en base a una demanda de ampliación de derechos a través de la protesta, sino a través de la idea de caridad y compasión. Finalmente, el pluralismo religioso es una peculiaridad de PRO. En efecto, este espacio político incluye figuras de estrechos lazos con la Iglesia católica, así como personalidades prominentes del judaísmo, el mundo evangélico y las filosofías new age, quienes exponen públicamente sus creencias. Esta diversidad refuerza la idea de que, más allá de las diferencias, existe una dimensión espiritual de la vida pública: desde la iniciativa moral muchos integrantes de $\mathrm{PRO}$ «se meten en política» para ayudar al prójimo «desde arriba».

El décimo capítulo, que representa el quinto bloque, señala la multiplicidad de desafíos al crecimiento del partido, de los cuales dos parecen especialmente relevantes: por un lado, la adhesión de los sectores populares y, por otro, su extensión a las provincias. Con respecto al primero de ellos, PRO enfrenta un dilema: ¿hacia dónde crecer? Los autores sostienen que la Argentina está dividida en dos clivajes de índole político-institucional y sociocultural. El problema consiste en que cada vez que PRO se acerca al voto populista (lo «bajo»), pierde sufragios del lado del electorado «alto", y lo contrario sucede cuando intenta captar el apoyo de este último polo. Por otra parte, constituirse en la "tercera vía» resulta una estrategia inviable ya que buena parte de la ciudadanía sigue pensándose como peronista o no peronista, de izquierda o derecha. Y si bien PRO ha intentado enarbolar los valores "posmateriales» para no ser identificado con la derecha, es pública su simpatía por el neoliberalismo y el conservadurismo. En relación a la segunda cuestión, PRO ha ofrecido su «marca» para la construcción de proyectos políticos en otros distritos lo que, a menudo, puso en relieve tanto la dificultad para conservar la unidad con cada filial como la intolerancia de la dirección del partido ante la independencia de sus miembros. Frente a esta realidad, PRO ha seguido la estrategia de ofrecer candidaturas a outsiders que responden directamente a Macri, lo que ha contribuido tanto a su crecimiento electoral en varias provincias como a la disminución de la autonomía de los políticos locales. Sin embargo, estas incorporaciones podrían dejar de tener un efecto positivo a mediano plazo porque la subordinación de los partidarios locales posiblemente sufra una merma si PRO no cosecha buenos resultados, al mismo tiempo que, tras una década de gestión, el encanto de Macri en tanto outsider podría desgastarse.

El trabajo de Bellotti, Morresi y Vommaro es un gran avance en la comprensión del fenómeno PRO ya que ofrece una explicación satisfactoria sobre sus orígenes, su lógica de funcionamiento, sus rituales partidarios, sus estrategias de 
expansión, las motivaciones de sus principales actores y los valores que rigen su visión de la política, al tiempo que sienta una base a partir de la cual la ciencia política y la sociología pueden pensar no sólo el porvenir del PRO, sino también la génesis y el panorama a futuro de otras fuerzas políticas novedosas de derecha en la región. En términos generales, sus conclusiones son sólidas gracias a la multiplicidad de fuentes que las sustentan, a saber: biografías, crónicas, entrevistas y encuestas por cuestionario realizadas a legisladores, diputados y comuneros de PRO y otros espacios políticos, funcionarios y ex funcionarios del gobierno de la ciudad, observación de actos partidarios y visitas a locales de PRO, centros barriales y comunas. También cabe destacar que si bien es una obra accesible para el público no especializado, ésta se nutre de una amplia bibliografía, vinculada principalmente a la teoría los partidos y sistemas de partidos que los autores no sólo retoman en sus explicaciones, sino que también discuten con buena parte de los estudios referenciados. Sin embargo, el balance de la gestión macrista resulta menos revelador debido a la escasez de fuentes y contribuciones académicas sobre las que se apoya. De este modo, el capítulo cuarto parece aproximarse más a una opinión basada en la compilación de noticias publicadas en los diarios, revistas, portales de noticias y blogs consultados, que a un trabajo exhaustivo de investigación. De todas formas, es imperativo subrayar el exiguo interés que han demostrado las ciencias sociales por el estudio de las políticas públicas que se implementan en la CABA, especialmente en áreas clave como desarrollo social, educación y salud, lo que dificulta seriamente la realización de una evaluación más objetiva sobre el impacto de la gestión PRO.

Finalmente, el tiempo dirá si PRO logrará sortear las limitaciones señaladas o si, por el contrario, Macri deberá postergar, una vez más, sus aspiraciones presidenciales ${ }^{1}$. Lo que es aún más incierto es si en caso de enfrentar la derrota este team leader será capaz de sujetar los fragmentos de su armado político como lo hizo luego de su primer traspié electoral en 2003, teniendo en cuenta que las condiciones de posibilidad para la emergencia de PRO se han transformado y que las ambiciones políticas de algunos de sus dirigentes podrían, tal vez, amenazar la posición del líder indiscutido.

\footnotetext{
${ }^{1}$ Nota del editor: la presente reseña fue entregada a Estudios Sociales con anterioridad a conocerse los resultados de las elecciones presidenciales de Argentina en 2015.
} 